\title{
Caracterização do Programa Nacional de Alimentação Escolar no Estado de Santa Catarina
}

\author{
Characterization of the National School \\ Food Program in Santa Catarina \\ State, Brazil
}

Patrícia Maria de Oliveira MACHADO'

Manuella de Souza MACHADO²

Bethsáida de Abreu Soares SCHMITZ1,2

Arlete Catarina Tittoni CORSO ${ }^{1,2}$

David Alejandro GONZÁLEZ-CHICA ${ }^{1,2}$

Francisco de Assis Guedes de VASCONCELOS 1,2

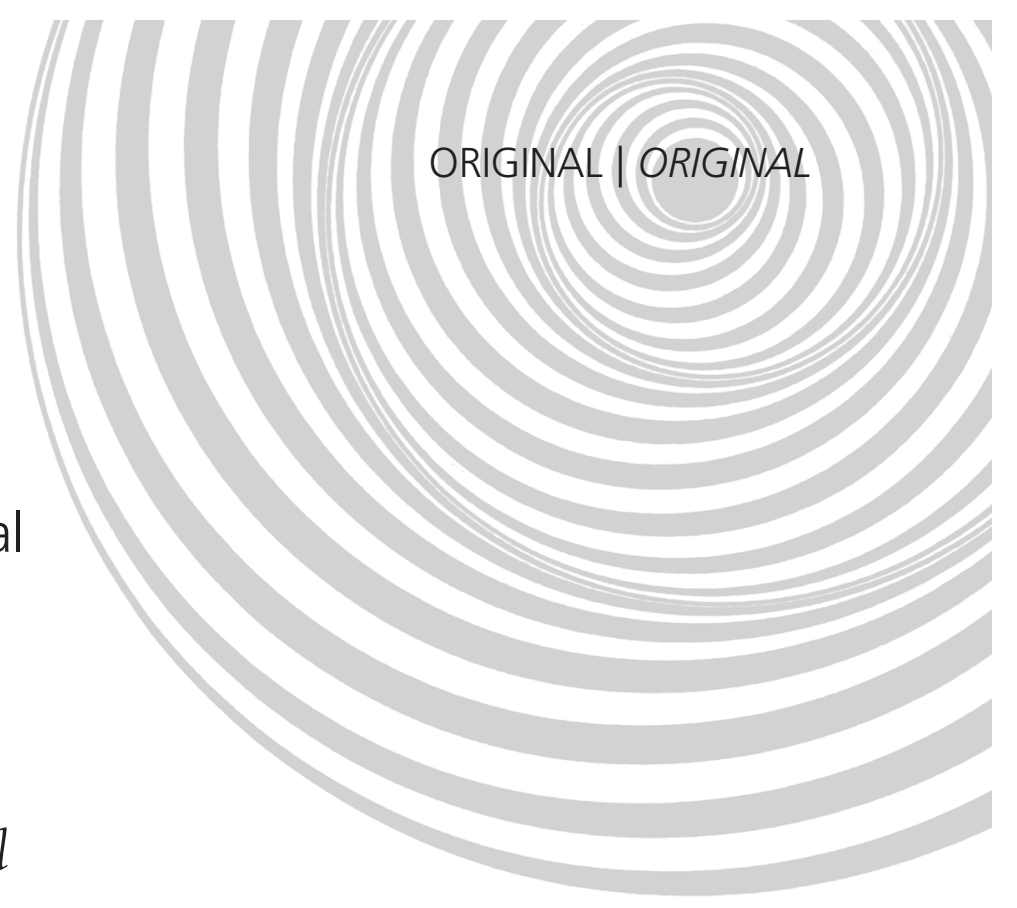

Francisco de Assis Guedes de VASCONCELOS

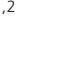


716 | PMO MACHADO et al.

(61,9\%). Destaca-se que 2,8\% dos municípios não possuíam responsável técnico e dois terços afirmaram que o custo médio por refeição servida variava entre $R \$ 0,31$ e $R \$ 0,90$, enquanto $21,6 \%$ informaram que o custo médio da refeição foi $\leq R \$ 0,30$. Não foi detectada diferença estatística significante em relação ao número de refeições por merendeira ao dia e ao custo médio da refeição entre os diferentes portes dos municípios ou índice de desenvolvimento humano $(p=0,584)$. Detectou-se adequação no número de nutricionistas por aluno matriculado estatisticamente maior nos municípios de pequeno porte $(p<0,001)$, assim com nos municípios de médio índice de desenvolvimento humano $(p<0,001)$.

\section{Conclusão}

Verifica-se inadequação da maioria dos municípios quanto ao número de nutricionistas. Percebeu-se a necessidade do estabelecimento de parâmetros mínimos de adequação entre número de merendeiras e refeições servidas, da necessidade de incentivos financeiros relacionados à mão de obra e custo das refeições.

Termos de Indexação: Alimentação escolar. Políticas públicas. Programas e políticas de nutrição e alimentação.

\section{A B S T R A C T}

\section{Objective}

To characterize the National School Food Program in Santa Catarina State.

\section{Methods}

This quantitative, exploratory, cross-sectional study used an online questionnaire to collect data from 293 municipalities in Santa Catarina from February to May 2010. The descriptive variables were analyzed according to their absolute and relative distributions. The software Stata 11.0 used the Chi-square test for comparing groups with a significance level of $5 \%(p<0.05)$.

\section{Results}

The questionnaire response rate was $74.4 \%$. Some municipalities had: centralized management of the National School Food Program (97.7\%); up to 10 schools (58.7\%); up to one thousand students enrolled in public schools (55.1\%); one dietician (91.7\%); up to ten cooks (49.5\%); and up to two thousand meals served per day (61.9\%). A few (2.8\%) municipalities did not have a technician in charge of the school food. The mean cost of each meal was $\leq R \$ 0.30$ in $21.6 \%$ of the municipalities and varied from $R \$ 0.31$ to $R \$ 0.90$ in two-thirds of the municipalities. Municipalities of different sizes or Human Development Indices had similar mean meal cost and number of meals prepared per cook per day $(p=0.584)$. Small municipalities $(p<0.001)$ and those with medium Human Development Indices $(p<0.001)$ were more likely to have a proper dietician-to-student ratio.

\section{Conclusion}

There is an inadequacy in most municipalities regarding the number of nutritionists. To establish minimum standards of adequacy between the number of cooks and meals served is necessary, beyond the need for financial incentives regarding workforce and meals costs.

Indexing terms: School feeding. Public policies. Food and nutrition programs and policies.

\section{N T R O D U ÇÃ O}

O Programa Nacional de Alimentação Escolar (PNAE) constitui-se uma intervenção governamental federal das mais antigas e permanentes no âmbito das políticas sociais brasileiras na área da alimentação e nutrição, sobretudo da população escolar ${ }^{1,2}$. Num período de 10 anos, o Programa passou por um processo de ressignificação em sua concepção como estratégia de promoção da alimentação saudável e adequada rumo à efetivação do Direito Humano à Alimentação Adequada (DHAA) e Segurança Alimentar e Nutricional $(\mathrm{SAN})^{3,4}$.

O movimento de descentralização da gestão do Programa em direção aos estados e municípios, propôs alternativas que aliassem eficiência e eficácia das ações do Estado à participação popular $^{5}$, possibilitando a oferta de uma alimentação escolar mais condizente com a cultura alimentar da população nas diferentes localidades do país ${ }^{6,7}$. Outro marco importante, sobretudo entre 
2003-2012, foi o estabelecimento de critérios técnicos e operacionais para a gestão da alimentação escolar pelos órgãos executores ${ }^{3,4}$, principalmente com a promulgação da Lei n 11.947 , de 16 de junho de 2009, que garantiu novos avanços ao PNAE, por meio da ampliação da clientela atendida, inserindo a educação alimentar e nutricional como um dos pilares do Programa, fortalecendo o controle social e, ainda, fomentando o desenvolvimento sustentável do mesmo ${ }^{8}$.

No ano de 2010, o PNAE atendeu 1354075 escolares da rede básica de educação no estado de Santa Catarina, beneficiando 5629 escolas, com um orçamento de $R \$ 88.277 .779,20$. Cabe ressaltar que $43 \%$ desse valor foram investidos com recursos próprios dos municípios ${ }^{9}$.

O estado de Santa Catarina, em 2010, era composto por 293 municípios que possuíam distribuição equilibrada em relação à população e à atividade econômica, uma vez que $72,3 \%$ dos municípios possuíam menos de 15 mil habi$\operatorname{tantes}^{10}$. O estado apresentava baixas taxas de analfabetismo, sendo de 1,2\% em 2010, ano em que a taxa nacional era de 9,6\% ${ }^{11}$. Destaca-se que nesse mesmo ano, $98 \%$ da população catarinense de 7 a 14 anos estava matriculada no sistema educacional ${ }^{9}$. O estado possuía o maior Produto Interno Bruto (PIB) per capita da região Sul e o quarto em nível nacional ${ }^{10}$. Estava dividido geograficamente em 6 macrorregiões (Sul, Vale do Itajaí, Norte, Grande Florianópolis, Serra e Oeste), cada uma dessas com polos econômicos de importância significativa para o desenvolvimento regional ${ }^{10-12}$.

Os estudos sobre gestão do PNAE, bem como da eficiência e da eficácia do Programa ainda são escassos no Brasil ${ }^{3}$ e em Santa Catarina $^{13}$. Uma pesquisa desenvolvida pelo Instituto Nacional de Estudos e Pesquisas Educacionais (INEP), com o objetivo de avaliar o processo de descentralização financeira do PNAE no ano de 1997, mostrou uma tendência de uniformidade e cumprimento das metas de qualidade e quantidade da alimentação escolar em todo o Brasil, porém não buscou associação entre os dados das diferentes regiões do Brasil e seus estados ${ }^{14}$.

Destaca-se que a descentralização da assistência técnica, juntamente com o estímulo às atividades de ensino, pesquisa e extensão por meio dos Centros Colaboradores de Alimentação e Nutrição do Escolar ${ }^{15}$, contribui para o aperfeiçoamento da gestão do PNAE e para uma maior aproximação da execução com os objetivos do Programa ${ }^{16,17}$.

Considerando o exposto, a pesquisa que gerou o presente artigo objetiva caracterizar a execução do PNAE quanto às variáveis relacionadas ao funcionamento do Programa e às possíveis associações com características dos municípios catarinenses.

\section{M É T O D O S}

O presente estudo foi realizado pelo Centro Colaborador de Alimentação e Nutrição do Escolar do Estado de Santa Catarina (CECANE/SC) abrangendo os 293 municípios catarinenses. Tratou-se de pesquisa quantitativa, de caráter exploratório e corte transversal. Para a coleta de dados elaborou-se questionário online, encaminhado por endereço eletrônico às Secretarias Municipais de Educação do Estado de Santa Catarina. Por meio desses endereços foi enviado o link de acesso à pesquisa e estabelecido o prazo de uma semana para os municípios responderem o protocolo.

A coleta de dados incluiu, ainda, levantamentos em fontes secundárias, tais como o último censo populacional do Instituto Brasileiro de Geografia e Estatística (IBGE) e o Atlas do Desenvolvimento Humano. Dessas fontes foram obtidas as variáveis para classificação do porte dos municípios ${ }^{18}$ e o Índice de Desenvolvimento Humano municipal $(\mathrm{IDH}-\mathrm{m})^{19}$.

Os dados do formulário online foram coletados entre fevereiro e maio de 2010, e transferidos automaticamente para uma planilha do programa Microsoft Exce ${ }^{\circledR}$. Posteriormente, os 
dados foram inseridos no software Stata ${ }^{\circledR} 11.0$ para a realização das análises estatísticas.

As variáveis analisadas de forma descritiva por meio da distribuição de frequência e consideradas no presente estudo como variáveis independentes foram: região do estado, porte do município, tipo e tempo de gestão do PNAE, número de escolas no município, número total de matrículas e por modalidade de ensino, número de nutricionistas, carga horária mensal do nutricionista, número de merendeiras, número de refeições por dia e custo médio da refeição servida. A variável porte do município foi categorizada conforme o número de habitantes. Municípios com menos de 20 mil habitantes foram considerados de pequeno porte, de 20 mil a 100 mil habitantes, de médio porte, e aqueles acima de 100 mil habitantes como de grande porte, conforme metodologia proposta pelo IBGE ${ }^{20}$.

Para os testes de associação as variáveis dependentes usadas foram: adequação do número de nutricionistas por alunos matriculados - classificados quanto ao cumprimento do número adequado de nutricionistas por alunos matriculados segundo a Resolução 358/2005 do Conselho Federal de Nutricionistas ${ }^{21}$ - e que foi analisada como variável dicotômica (sim/não); número de refeições servidas por merendeiras por dia, que foi calculada realizando a proporção entre os dados de número de merendeiras e refeições servidas no município; e custo médio da refeição per capita. As variáveis independentes foram o porte do município e o IDH-m.

As análises estatísticas realizadas foram adequadas à simetria das variáveis estudadas, considerando a utilização do coeficiente de variação e o teste de Shapiro-Wilk. Inicialmente, procedeu-se análise descritiva para caracterização da amostra com utilização de frequências absolutas e relativas. Para comparação entre as prevalências das variáveis dependentes e independentes utilizou-se teste do Qui-quadrado $\left(\chi^{2}\right)$ com correção de Yates para as variáveis categóricas, sendo o valor $p<0,05$ considerado significativo.
O projeto foi aprovado: 1) pelo Comitê de Ética em Pesquisa com Seres Humanos (CEPSH), da Universidade Federal de Santa Catarina, sob o parecer n²34/09; e 2) pela Comissão Nacional de Ética em Pesquisa (CONEP), com a Folha de Rosto número 278178.

\section{RES U L T A D OS}

Do total de 293 municípios existentes no estado foram obtidas informações de 218 , correspondendo a uma taxa de resposta de $74,4 \%$. A Tabela 1 apresenta as características dos municípios, a sua distribuição e o tipo de gestão. Quase $40 \%$ dos municípios respondentes pertenciam à região Oeste do estado, seguido pelo do Vale de Itajaí (19,3\%). As demais regiões tiveram participação de aproximadamente $10 \%$ dos municípios. A maioria dos municípios foi classificada como de pequeno porte (83\%), enquanto apenas nove $(4,1 \%)$ foram considerados de grande porte. Quase todos os municípios referiram ter um sistema de gestão centralizado da alimentação escolar $(97,7 \%)$, sendo que apenas dois municípios apresentavam gestão escolarizada, e outros dois, gestão terceirizada. Apenas um apresentou um sistema de gestão semiterceirizada. Vale destacar que os três municípios com sistema de gestão terceirizada ou semiterceirizada são todos de grande porte e iniciaram esses sistemas de gestão entre 2005 e 2007.

De acordo com a Tabela 2, pouco mais da metade dos municípios possuíam menos do que 10 escolas e apenas 8 municípios têm 50 ou mais escolas na sua jurisdição. Em torno de $55 \%$ dos municípios tiveram menos de mil alunos matriculados no último ano. Quase a totalidade dos municípios do estado $(91,7 \%)$ contava com apenas um nutricionista como Responsável Técnico (RT) do PNAE, não apresentando mais profissionais de nutrição em seu Quadro Técnico (QT). Destaca-se que 6 municípios (2,8\%), todos de pequeno porte, afirmaram não possuir nenhum profissional da nutrição. A carga horária mensal dos nutricionistas foi inferior a 80 horas em 74,3\% 
Tabela 1. Caracterização do Estado de Santa Catarina segundo regiões, porte dos municípios, e tipo e tempo de gestão do Programa Nacional de Alimentação Escolar (PNAE), 2010.

\begin{tabular}{lcc}
\hline Variável & $\mathrm{n}$ & Prevalência \\
\hline Municípios por região do estado & & \\
Oeste & 86 & 39,5 \\
Norte & 22 & 10,1 \\
Serrana & 24 & 11,0 \\
Vale do Itajaí & 42 & 19,3 \\
Grande Florianópolis & 14 & 6,4 \\
Sul & 30 & 13,8 \\
Porte do município* (habitantes) & & \\
Pequeno (<20 000) & 181 & 83,0 \\
Médio (20-100 000) & 28 & 12,8 \\
Grande (>100 000) & 9 & 4,1 \\
Tipo de gestão do PNAE & & \\
Centralizada & 213 & 97,7 \\
Escolarizada & 2 & 0,9 \\
Terceirizada & 2 & 0,9 \\
Mista & 1 & 0,5 \\
Tempo de gestão (anos) do PNAE & & \\
1-5 & 8 & 3,7 \\
6-15 & 5 & 2,3 \\
Sempre foi assim & 205 & 94,0 \\
\hline Total & 218 & 100,0 \\
\hline
\end{tabular}

Fonte: *Instituto Bra sileiro de Geografia e Estatística ${ }^{18}$.

dos municípios, sendo que em apenas $10 \%$ dos casos o tempo de trabalho foi superior a 160 horas. Quase a metade dos municípios referiu contar com até 10 merendeiras trabalhando nas escolas, e um terço referiram possuir número superior a 20 funcionárias/merendeiras. Dois terços dos municípios relataram preparar menos do que 2 mil refeições por dia letivo, e também dois terços afirmaram que o custo médio por refeição servida variava entre $R \$ 0,31$ e $R \$ 0,90$. Destaca-se que $21,6 \%$ dos municípios informaram que o custo médio da refeição foi igual ou inferior à $R \$ 0,30$, enquanto $7,8 \%$ apresentaram o custo médio superior à $R \$ 1,20$.

A Tabela 3 apresenta a associação entre as variáveis de adequação do número de nutricionistas por aluno matriculado, refeições servidas por merendeira e custo das refeições, com as características de porte e IDH dos municípios.
Tabela 2. Distribuição das características da alimentaçãao escolar nos municípios do Estado de Santa Catarina quanto ao quantitativo de escolas, escolares matriculados, nutricionistas, carga horária mensal dos nutricionistas, merendeiras, refeições e custo médio da refeição, 2010.

\begin{tabular}{|c|c|c|}
\hline Variável & $n$ & Prevalência \\
\hline \multicolumn{3}{|c|}{ Número de escolas no município } \\
\hline$\leq 4$ & 60 & 27,5 \\
\hline $5-9$ & 68 & 31,2 \\
\hline 10-19 & 56 & 25,7 \\
\hline $20-49$ & 26 & 11,9 \\
\hline$\geq 50$ & 8 & 3,7 \\
\hline \multicolumn{3}{|c|}{ Número total alunos matriculados } \\
\hline$\leq 500$ & 68 & 31,2 \\
\hline $501-1000$ & 52 & 23,9 \\
\hline $1001-2500$ & 56 & 25,7 \\
\hline $2501-5000$ & 21 & 9,6 \\
\hline$>5000$ & 21 & 9,6 \\
\hline \multicolumn{3}{|c|}{ Número de nutricionistas } \\
\hline Sem RT & 6 & 2,89 \\
\hline 1 nutricionista & 200 & 1,7 \\
\hline$\geq 2$ nutricionistas & 12 & 5,5 \\
\hline \multicolumn{3}{|c|}{ Carga horária mensal de nutricionistas } \\
\hline 20 & 64 & 29,5 \\
\hline $21-40$ & 37 & 17,0 \\
\hline $41-80$ & 62 & 28,6 \\
\hline $81-160$ & 32 & 14,8 \\
\hline$>160$ & 22 & 10,1 \\
\hline \multicolumn{3}{|c|}{ Número de merendeiras } \\
\hline$\leq 5$ & 46 & 21,1 \\
\hline $6-10$ & 62 & 28,4 \\
\hline $11-20$ & 40 & 18,4 \\
\hline $21-50$ & 45 & 20,6 \\
\hline$>50$ & 25 & 11,5 \\
\hline \multicolumn{3}{|c|}{ Número de refeições por dia letivo } \\
\hline$<1000$ & 85 & 39,0 \\
\hline 1000-1999 & 50 & 22,9 \\
\hline 2000-3999 & 44 & 20,2 \\
\hline 4000-7999 & 16 & 7,3 \\
\hline$\geq 8000$ & 23 & 10,6 \\
\hline \multicolumn{3}{|c|}{ Custo médio por refeição servida (Reais) } \\
\hline $0,10-0,30$ & 47 & 21,6 \\
\hline $0,31-0,60$ & 91 & 41,7 \\
\hline $0,61-0,90$ & 42 & 19,3 \\
\hline $0,91-1,20$ & 21 & 9,6 \\
\hline$>1,20$ & 17 & 7,8 \\
\hline Total & 218 & 100,0 \\
\hline
\end{tabular}

Nota: RT: Responsável Técnico. 
Destaca-se que os municípios de porte médio e grande demonstraram maior inadequação do número de nutricionistas pelo número de alunos matriculados $(97,4 \%)$, sendo que entre os pequenos municípios, apesar do percentual de inadequação ter se apresentado um pouco menor, ainda incluiu mais da metade deles $(63,4 \%)$, sendo que a associação mostrou-se estatisticamente significativa. Nos municípios com maior IDH municipal foi encontrado maior percentual de inadequação, 83,3\% $(p<0,001)$.

O número de refeições por merendeira ao dia não apresentou diferença estatística significante entre os diferentes portes dos municípios $(p=0,093)$ ou IDH $(p=0,584)$. Dessa forma, a maioria dos municípios serviu entre 100 e 249 refeições por merendeira ao dia, independente do porte do município (45,3\% dos municípios de pequeno porte, $57,1 \%$ dos municípios de médio e grande porte) e do IDH (50,8\% dos municípios de médio IDH e $44,0 \%$ dos municípios de alto IDH). Destaca-se que $44,8 \%$ dos municípios de peque-no porte e $44,0 \%$ dos municípios de alto
IDH serviam até 99 refeições por merendeira ao dia, enquanto $17,9 \%$ dos municípios de médio e grande porte e $12,0 \%$ dos municípios de alto IDH serviam acima de 250 refeições por merendeira ao dia. O custo médio da refeição também não apresentou diferença estatística significante de acordo com o porte dos municípios $(p=0,141)$ ou com o IDH $(p=0,71)$ (Tabela 3).

Considerando que foram poucos municípios encontrados com gestão terceirizada ou mista não foi possível estabelecer associações estatísticas em relação à modalidade de gestão e demais variáveis.

\section{DIS CUSS Ã O}

O presente estudo identificou que a maioria dos municípios catarinenses realizava a execução administrativo-financeira do PNAE de forma centralizada, sendo essa o tipo de gestão responsável por todas as etapas entre o planejamento e a distribuição da alimentação escolar22-24. Uma pesquisa sobre o perfil da gestão pública do PNAE

Tabela 3. Associação entre adequação do número de nutricionistas por aluno matriculado, refeições servidas por merendeira e custo das refeições com as características de porte e Índice de Desenvolvimento Humano (IDH) municipal no Estado de Santa Catarina, 2010

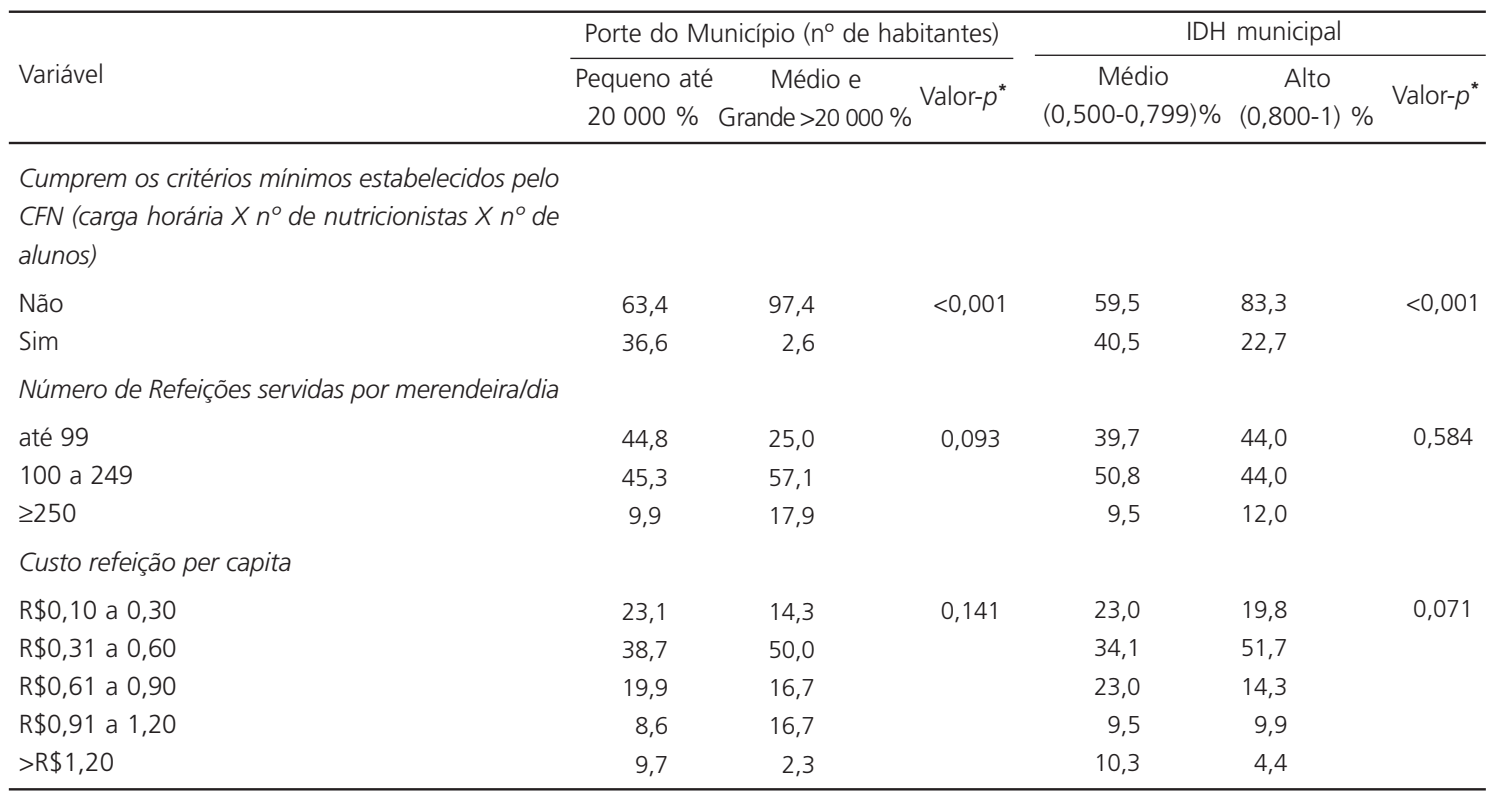

Nota: *Teste de Qui-quadrado; CFN: Conselho Federal de Nutrição; IDH: Índice de Desenvolvimento Humano. 
em 670 prefeituras inscritas no Prêmio Gestor Eficiente da Alimentação Escolar de 2004 e 2005, também observou a centralização como forma preponderante de gestão entre os municípios. Os autores apontaram como uma vantagem dessa forma de gestão ${ }^{25}$, a possibilidade de realizar um controle eficaz de todo o processo - além da possibilidade de vistoriar a qualidade dos produtos e dos cardápios em todas as escolas do município.

Cabe ressaltar que alguns gestores optam pela contratação de empresas privadas para gerenciar a alimentação escolar, no denominado sistema terceirizado. Em geral, os executores pagam pelo número de refeições servidas mensalmente, estando embutidos nessa cobrança unitária todos os serviços prestados pela empresa contratada. Ressalta-se que na gestão terceirizada os recursos repassados pelo Fundo Nacional de Desenvolvimento da Educação (FNDE) à prefeitura somente podem ser utilizados para a compra de gêneros alimentícios ${ }^{26}$.

Em Santa Catarina verificou-se que apenas 2 municípios (cerca de 1\%) apresentaram esse modelo de gestão. Da mesma forma, a análise das prefeituras inscritas no Prêmio Gestor Eficiente da Alimentação Escolar constatou que uma pequena parcela (2,9\% dos casos, ou seja, 11 prefeituras inscritas em 2004, e 2,4\%, 7 prefeituras em 2005), utilizava o sistema terceirizado. Os autores ainda questionam a gestão terceirizada pelo fato dela exigir maiores investimentos (há a necessidade de pagamento não apenas pelo alimento servido, mas também pelo serviço prestado), além da lógica de funcionamento de uma empresa privada diferir daquela praticada na administração pública ${ }^{25}$.

No estado de São Paulo tal modalidade tem sido implementada desde a década de 1990, no entanto, existem experiências de retorno à municipalização da gestão do PNAE devido à baixa qualidade dos serviços e superfaturamento da alimentação escolar? ${ }^{7}$.

Quanto à responsabilidade técnica pela execução do PNAE, quase a totalidade dos municípios em Santa Catarina contava com um nutri- cionista para esta função (cerca de 92\%), independente do número de unidades escolares e de estudantes, sendo que alguns municípios (cerca de $3 \%$ ) encontravam-se sem nenhuma assessoria profissional em nutrição. A Lei no 11.947 , de 16 de junho de 2009, estabelece ser o nutricionista o responsável técnico pela execução do Programa, e único profissional competente na elaboração de cardápios que assegurem a segurança alimentar e nutricional, além de hábitos alimentares saudáveis ${ }^{8}$.

O Conselho Federal de Nutricionistas (CFN), no âmbito da alimentação escolar, dispõe sobre as atribuições do nutricionista no Programa Nacional de Alimentação Escolar. Em agosto de 2010 foi publicada a Resolução do CFN $n^{\circ}$ 465/2010, que estabelece uma carga horária mínima para um responsável técnico pelo Programa, o total de 30 horas semanais para entidades executoras com até 500 alunos $^{27}$. No entanto, à época da coleta de dados deste estudo vigorava a Resolução do CFN n 358/2005, cujos parâmetros numéricos ditavam a necessidade de um nutricionista responsável técnico com 20 horas para as modalidades de ensino em período parcial e para o Ensino Fundamental em período integral21.

Considerando-se que três quartos dos nutricionistas possuíam carga horária mensal de até 80 horas, ou seja, menos de 20 horas semanais, pode-se afirmar que a maior parte dos municípios não cumpre os critérios mínimos exigidos pelo CFN. Essa realidade pode ficar ainda mais distante do preconizado pela legislação se considerarmos que a maioria dos municípios pesquisados possui mais de 500 alunos $(68,8 \%)$ e, portanto, deveriam ter mais de um nutricionista atuando no PNAE.

De acordo com a Resolução do CFN n ${ }^{\circ}$ 465/2010, é de competência do nutricionista a elaboração de cardápios que atendam as recomendações nutricionais propostas pelo FNDE, conforme o perfil epidemiológico dos escolares, respeitando os hábitos alimentares culturais e a vocação agrícola local, procurando comprar ali- 
mentos provenientes da agricultura familiar, com prioridade aos gêneros orgânicos; planejar, orientar e supervisionar a execução do Programa; realizar atividades de educação nutricional à toda comunidade escolar; elaborar o Manual de boas Práticas para as unidades escolares; elaborar o plano anual de trabalho do PNAE; estimular o diagnóstico e atendimento adequado de portadores de necessidades nutricionais específica ${ }^{27}$. Dessa forma, a inadequação do número de nutricionistas pode comprometer o desenvolvimento de todas as atribuições previstas pelo CFN, ou dificultar o cumprimento das ações de forma adequada $^{28}$ na maioria dos municípios catarinenses.

A presente pesquisa demonstrou que cerca da metade dos municípios possui até 10 merendeiras. Considerando que a maioria dos municípios é de pequeno porte e possui até 10 escolas (58,7\%), estimou-se que cada município possuía uma merendeira por escola. Além disso, na maioria dos municípios o número de refeições por merendeira foi alto (entre 100 e 149 refeições por merendeira ao dia), independente do porte, e do IDH dos municípios. Destaca-se o alto nível de doenças decorrentes do processo de sobrecarga de trabalho, desgaste e repetição de tarefas entre estes profissionais ${ }^{29,30}$. Salienta-se que não há na literatura uma orientação quanto ao critério de número de refeições por merendeiras. Tal fato se deve aos inúmeros fatores que interferem nesta relação, tais como os equipamentos disponíveis nas cozinhas, a utilização de alimentos beneficiados ou in natura, a complexidade do cardápio e das preparações ${ }^{31,32}$.

O alto número de refeições por merendeiras pode prejudicar o desempenho profissional, dificultando a execução de uma alimentação segura e saudável, de acordo com o cardápio planejado e conforme as boas práticas de manipulação. Estudo qualitativo com merendeiras de 41 escolas públicas de João Pessoa afirma a relevância das merendeiras no contexto do PNAE, como atores fundamentais para utilização da alimentação escolar como espaço permanente de apren- dizado, evidenciando a necessidade de um olhar mais atento para as potencialidades desse profissional, com maior suporte técnico no seu processo de trabalho ${ }^{33}$.

O custo unitário das refeições escolares é um tema que requer maiores discussões no plano da gestão federal, uma vez que as diferenças regionais do custo de alimentos não são contempladas. Além disso, o financiamento do PNAE pelo governo federal existe em caráter suplementar, exclusivo para a compra de gêneros alimentícios, cabendo aos estados e municípios a complementação financeira no fornecimento da alimentação escolar, além de estrutura física e mão-de-obra ${ }^{8,29}$.

Os valores de repasse federal per capita por dia letivo no momento da coleta de dados, em 2010, eram de $R \$ 0,30$ para escolas de ensino fundamental, médio e EJA; R\$0,60 para creches, escolas básicas indígenas e quilombolas; e $\mathrm{R} \$ 0,90$ para os alunos participantes do Programa Mais Educação ${ }^{23,24}$. A maioria dos municípios apresentou o custo médio das refeições (considerando gêneros alimentícios e outros itens) entre $R \$ 0,31$ e $R \$ 0,60$, independente do porte e do IDH do município.

Tomando-se por referência o valor de $\mathrm{R} \$ 0,30$, aplicado na maior parte dos escolares, percebe-se que $21,6 \%$ dos municípios apresentaram um custo médio por refeição inferior ao repasse do FNDE, portanto, sem contrapartida. Destaca-se que os valores de repasse do Governo Federal para o PNAE foram alterados em 2012, sendo que para a creche e pré-escola os mesmos foram reajustados em 2012 para $R \$ 1,00$ e $R \$ 0,50^{24}$.

Neste sentido, observa-se a necessidade real de complementação financeira da alimentação escolar por parte do município, de forma a garantir uma alimentação escolar dentro de princípios que promovam a segurança alimentar e nutricional. Em Santa Catarina verificam-se distintas influências culturais nos hábitos alimentares da população, nas várias regiões do estado, além de iniciativas comprometidas com a quali- 
dade da alimentação escolar, como a Lei Estadual $n^{\circ} 12.061$ de 2001, que regulamenta os alimentos comercializados no ambiente escolar e os incentivos pioneiros ao consumo de alimentos oriundos da agricultura orgânica e familiar ${ }^{34,35}$.

Os resultados indicaram inadequação dos municípios quanto à contratação do responsável técnico para a execução do PNAE, ou seja, o nutricionista, havendo necessidade de fiscalização dessa condição. Cabe, aqui, ressaltar a necessidade das normativas propostas pelos conselhos profissionais no Brasil possuírem peso de lei em relação à administração pública; uma vez que os conselhos regulamentam o exercício profissional, entende-se que sua legislação recai apenas sob o profissional fiscalizado ${ }^{36}$. No caso das merendeiras ressalta-se a necessidade do estabelecimento de parâmetros mínimos de adequação entre número de merendeiras e refeições servidas e/ou alunos matriculados, a fim de assegurar a qualidade dos serviços e da mão-de-obra.

Pode-se perceber que o custo médio per capita com a alimentação escolar foi maior que o valor repassado pelo FNDE na maioria dos municípios. Sendo assim, considera-se necessário analisar os custos com a alimentação escolar para além do investimento total em gêneros alimentícios. Outros estudos também indicam a necessidade de incentivos diferenciados às diversas realidades regionais, no que concerne à infraestrutura, mão-de-obra e apoio à contratação dos responsáveis técnicos e à gestão do Progra$\mathrm{ma}^{22,25,29,37 \text {. }}$.

Os achados apontam para a necessidade de melhoria da execução do PNAE pelos municípios, capacitação de gestores e, principalmente, dos Conselhos de Alimentação Escolar (CAE) que têm focado sua atuação na análise de prestação de contas e na fiscalização de recursos em Santa Catarina ${ }^{13}$ além de acompanhar a elaboração dos cardápios $^{38}$, apontando para a emergente mudança de escopo para o reconhecimento de outras atribuições do $C A E^{13}$, como a pactuação de prioridades de investimentos pela gestão.

\section{ONCLUSÃO}

Este estudo procurou caracterizar o PNAE no estado de Santa Catarina, a partir de variáveis relacionadas ao seu funcionamento/gestão de acordo com características sociodemográficas municipais. Entre os principais achados do estudo destacam-se: a maioria dos municípios do estado com gestão centralizada da alimentação escolar, a inadequação da carga horária e do número de nutricionistas em relação aos alunos matriculados, a inexistência de critérios para o número de merendeiras, a necessidade de incentivos financeiros relacionados à mão de obra e custo das refeições, além da possibilidade de incentivos diferenciados regionalmente segundo as distintas realidades municipais.

Apesar do foco deste trabalho não ser uma avaliação da efetividade, com base na qualidade e quantidade de alimentação escolar; destaca-se a relevância dos dados aqui apresentados sobre a gestão da alimentação escolar, face à escassez de estudos, fundamentais para o fornecimento de subsídios aos gestores públicos, de forma a favorecer o aprimoramento da execução do Programa.

A existência de estudos pode auxiliar na investigação das diferentes características do PNAE em distintos contextos regionais, justificando a iniciativa deste estudo em Santa Catarina e, indicando desde já, a necessidade de outras pesquisas nesta área em outras realidades, principalmente no que concerne a adequação do número de nutricionistas e merendeiras por alunos.

\section{REFERÊ NCIAS}

1. Spinelli MAS, Canesqui AM. O programa de alimentação escolar no estado de Mato Grosso: da centralização à descentralização (1979-1995). Rev Nutr. 2002 [acesso 2013 maio 2]; 15(1):105-17. Disponível em: <http://www.scielo.br/scielo/rn>. doi: 10.1590/S1415-52732002000100011.

2. Spinelli MAS, Canesqui, AM. Descentralização do programa de alimentação escolar em Cuiabá: 
1993-1996. Rev Nutr. 2004 [acesso 2013 maio 2]; 17(2):151-65. Disponível em: <http://www.scielo. br/scielo/rn>. doi: 10.1590/s1415-52732004000 200002.

3. Vasconcelos FAG. Programa nacional de alimentação escolar: limites e possibilidades para a garantia do direito humano à alimentação adequada, saudável e sustentável. Ciênc Saúde Colet. 2013 [acesso 2013 jul 6]; 18(4):906-6. Disponível em: <http://www.scielo.br/scielo>. doi: 10.1590/S141 3-81232013000400001.

4. Peixinho AML. A trajetória do programa nacional de alimentação escolar no período de 2003-2010: relato do gestor nacional. Ciênc Saúde Colet. 2013 [acesso 2013 jul 6]; 18(4):909-16. Disponível em: <http://www.scielo.br>. doi: 10.1590/S1413-81 232013000400002.

5. Pipitone MAP, Ometto $A M H$, Silva $M V$, Sturion $G L$, Furtuoso MCO, Oetterer M. Atuação dos conselhos municipais de alimentação escolar na gestão do programa nacional de alimentação escolar. Rev Nutr. 2003 [acesso 2013 maio 2]; 16(2):143-54. Disponível em: <http://www.scielo.br>. doi: 10.15 90/S1415-52732003000200001.

6. Belik W, SILVA JG, Takagi M. Políticas de combate à fome no Brasil. São Paulo Perspec. 2001 [acesso 2012 dez 2]; 15(4):119-29. Disponível: <http:// www.scielo.br>. doi: 10.1590/S0102-883920010 00400013.

7. Santos LMP, Santos SMC, Santana LAL, Henrique FCS, Mazza RPD, Santos LAS, et al. Avaliação de políticas públicas de segurança alimentar e combate à fome no período 1995-2002: 4 - Programa Nacional de Alimentação Escolar. Cad Saúde Pública. 2007 [acesso 2012 dez 7]; 23(11):2681-93. Disponível em: <http://www.scielo.br>. doi: 10.1590/ S0102-311X2007001100016.

8. Brasil. Lei $n^{\circ} 11.947$, de 16 de junho de 2009. Dispõe sobre o atendimento da alimentação escolar e do programa dinheiro direto na escola aos alunos da educação básica. Diário Oficial da União. 2009 16 jun.

9. Brasil. Ministério da Educação. Painel de Controle do MEC. Pesquisa assuntos educacionais: Santa Catarina. Brasília: MEC; 2010 [acesso 2012 dez 12]. Disponível em: <http://painel.mec.gov.br/painel/ detalhamentolndicador/detalhes/estado/estuf/SC>.

10. Theis IM, Butzke L, Rischbieter ILK, Linder MC, Vargas DB. O cavalo de Tróia e sua barriga verde: planejamento regional e desigualdades socioespaciais em Santa Catarina. Rev Paraná Desenv. 2011 [acesso 2013 mar 14]; 120(1):39-56. Disponível em: <http://www.ipardes.pr.gov.br/ojs/index.php/ revistaparanaense/article/view/345/668>.

11. Santa Catarina. Secretaria do Estado da Educação. Portal da Educação. Análise do analfabetismo em Santa Catarina em 2010. [acesso 2013 mar 14].
Disponível em: <http://www.sed.sc.gov.br/ secretaria/noticias>.

12. Seabra F, Bez FC, Bornschein FC. O efeito litoralização e a distribuição regional de renda e de população em Santa Catarina. Ens FEE. 2011 [acesso 2012 ago 23]; 32(1):197-216. Disponível em: <http://revistas.fee.tche.br/index.php/ensaios/ article/view/2285>.

13. Gabriel CG, Machado MS, Schmitz BAS, Corso ACT, Caldeiras GV, Vasconcelos FAG. Conselhos municipais de alimentação escolar em Santa Catarina: caracterização e perfil de atuação. Ciênc Saúde Colet. 2013 [acesso 2013 set 2]; 18(4):971-8. Disponível em: <http://www.scielosp.org/scielo.php?script= sci_arttext\&pid=S1413-81232013001000009 \&lng=en>. doi: 10.1590/S1413-812320130010 00009.

14. Brasil. Ministério da Educação. Avaliação da descentralização de recursos do FNDE e da merenda escolar: síntese dos resultados. Brasília: MEC; 1998 [acesso 2012 abr 12]. Disponível em: <http://www. dominiopublico.gov.br/download/texto/me002 746. pdf>.

15. Brasil. Portaria Interministerial $n^{\circ} 1010$, de 8 de maio de 2006. Institui as diretrizes para a promoção da alimentação saudável nas escolas de educação infantil, fundamental e nível médio das redes públicas e privadas, em âmbito nacional Brasília: Ministério da Educação; 2006 [acesso 2012 abr 12]. Disponível em: <www.fnde.gov.br/index.php/.../ 283-por101008052006/download>.

16. Santos LAS, Carvalho DMM, Reis ABC, Ramos LB, Freitas MCS. Formação de coordenadores pedagógicos em alimentação escolar: um relato de experiência. Ciênc Saúde Colet. 2013 [acesso 2013 jul 6]; 18(4):993-1000. Disponível em: <http://www. scielo.br>. doi: 10.1590/S1413-8123201300 0400012

17. Scarparo ALS, Oliveira VR, Bittencourt JMV, Ruiz ENF, Fernandes PF, Zys JZ, et al. Formação para nutricionistas que atuam no programa nacional de alimentação escolar: uma avaliação da efetividade. Ciênc Saúde Colet. 2013 [acesso 2013 jul 6]; 18(4):1001-8. Disponível em: <http://www. scielo. br>. doi: 10.1590/S1413-81232013000400013.

18. Instituto Brasileiro de Geografia e Estatística. Censo Demográfico 2010. [acesso 2012 abr 12]. Disponível em: <http://www.ibge.gov.br/home/estatistica/ populacao/censo2010/default.shtm>.

19. Brasil. Programa das Nações Unidas para o Desenvolvimento. Atlas do desenvolvimento humano no Brasil. Brasília: PNUD; 2000 [acesso 2013 abr 20]. Disponível em: <http://www.pnud.org.br/atlas/ tabelas/index.php>.

20. Instituto Brasileiro de Geografia e Estatística. Síntese de indicadores sociais: uma análise das condições 
de vida da população brasileira. Rio de Janeiro: IBGE; 2010 [acesso 2012 set 22]. Disponível em: <http://www.ibge.gov.br/home/estatistica/ populacao/condicaodevida/indicadoresminimos/ sinteseindicsociais2010/SIS_2010.pdf>.

21. Conselho Federal de Nutricionistas. Resolução CFN $n^{\circ} 358 / 2005$. Dispõe sobre as atribuições do nutricionista em âmbito do programa de alimentação escolar (PNAE) e dá outras providências. Diário Oficial da União. 200518 de maio.

22. Nogueira MR. O programa nacional de alimentação escolar como uma política nacional pública: o caso de Campinas-SP [dissertação]. Campinas: Unicamp; 2005.

23. Brasil. Fundo Nacional de Desenvolvimento da Educação. Programa nacional de alimentação escolar: funcionamento. [acesso 2012 ago 23]. Disponível em: <http://www.fnde.gov.br/programas/ alimentacao-escolar/alimentacao-escolarfuncionamento>.

24. Brasil. Fundo Nacional de Desenvolvimento da Educação. Programa nacional de alimentação escolar: apresentação. [acesso 2012 ago 23]. Disponível em: <http://www.fnde.gov.br/programas/ alimentacao-escolar/alimentacao-escolarapresentacao>.

25. Belik W, Chaim NA. O programa nacional de alimentação escolar e a gestão municipal: eficiência administrativa, controle social e desenvolvimento local. Rev Nutr. 2009 [acesso 2013 mar 7]; 22(5): 595-607. Disponível em: <http://www.scielo.br/ rn>. doi: 10.1590/S1415-52732009000500001.

26. Brasil. Resolução CD/FNDE n 38, de 16 de julho de 2009. Dispõe sobre o atendimento da alimentação escolar aos alunos da educação básica no Programa Nacional de Alimentação Escolar - PNAE. Diário Oficial da União. 2009 [acesso 2012 abr 12]. 17 jul; Seção 1. Disponível em: <http://www.fnde. gov.br/arquivos/category/22-2009? download= 57:res038-16072009>.

27. Conselho Federal de Nutricionistas. Resolução CFN $n^{\circ} 465 / 2010$. Dispõe sobre as atribuições do nutricionista, estabelece parâmetros numéricos mínimos de referência no âmbito do Programa de Alimentação Escolar (PAE) e dá outras providências. Diário Oficial da União. 201025 ago.

28. Chaves LG, Santana TCM, Gabriel CG, Vasconcelos FAG. Reflexões sobre a atuação do nutricionista no programa nacional de alimentação escolar no Brasil. Ciênc Saúde Colet. 2013 [acesso 2013 jul 6]; 18(4):917-26. Disponível em: <http://www.scielo. br>. doi: 10.1590/S1413-81232013000400003.

29. Bezerra JAB. Regionalização de cardápios, fortalecimento das economias locais e participação da população na gestão descentralizada da merenda escolar. Educ Debate. 2006; 28(51/5):86-93.
30. Druck G, Franco TMA. A precarização do trabalho no Brasil: um estudo da evolução da terceirização no Brasil e na indústria da Bahia na última década. RELET. 2008 [acesso 2012 ago 14]; 13(1):97-120. Disponível em: <http:// www.repositorio.ufba.br/ri/ handle/ri/3154>.

31. Miron VR, Stefanello CL, Mattos KM, Colome JS, Costenaro R, Carpes AD. Profissão merendeira: perfil profissional e condições socioeconômicas. Disciplinarum Scientia. 2009 [acesso 2013 mar 7]; 10(1):87-95. Disponível em: <http://sites.unifra.br/ Portals/36/CSAUDE/2009/09.pdf>.

32. Nunes BO. O sentido do trabalho para merendeiras e serventes em situação de readaptação nas escolas públicas do Rio de Janeiro [dissertação]. Rio de Janeiro: Fiocruz; 2000.

33. Carvalho AT, Muniz VM, Gomes JF, Samico I. Programa de alimentação escolar no município de João Pessoa - PB, Brasil: as merendeiras em foco. Interface. 2008 [acesso 2013 mar 7]; 12(27): 823-34. Disponível em: <http://www.scielo.br>. doi: 10.1590/S1414-32832008000400012.

34. Gabriel CG, Santos MV, Vasconcelos FAG, Milanez GHG, Hulse SB. Cantinas escolares de Florianópolis: existência e produtos comercializados após a instituição da Lei de Regulamentação. Rev Nutr. 2010 [acesso 2013 ago 14]; 23(2):191-9. Disponível: <http://www.scielo.br/rn>. doi: 10.15 90/S14 15-52732010000200002.

35. Lima EE, Sousa AA. Alimentos orgânicos na produção de refeições escolares: limites e possibilidades em uma escola pública em Florianópolis. Rev Nutr. 2011 [acesso 2013 ago 14]; 24(2):263-73. Disponível: <http://www.scielo.br/rn>. doi: 10.15 90/S1415-52732011000200007.

36. Rezende MTMC. O papel social dos conselhos profissionais na área da saúde. Rev Soc Bras Fonoaudiol. 2007 [acesso 2013 maio 14]; 12(1):8-10. Disponível em: <http://www.scielo.br/scielo.php?script=sci_ arttext\&pid=S1516-80342007000100002> .

37. Paiva, JB. Hábitos alimentares regionais no âmbito do programa nacional de alimentação escolar em um município do sertão Baiano: uma abordagem qualitativa [dissertação]. Salvador: Universidade Federal da Bahia; 2011.

38. Bandeira LM, Chagas CMS, Gubert MB, Toral M, Monteiro RAI. Análise dos pareceres conclusivos dos conselhos de alimentação escolar sobre a execução do programa nacional de alimentação escolar. Rev Nutr. 2013 [acesso 2013 set 2]; 26(3):343-51. Disponível em: <http://www.scielo.br/rn>. doi: 10.1590/S1415-52732013000300009.

Recebido em: 20/5/2013 Versão final em: 7/10/2013 Aprovado em: 11/10/2013 
